\title{
Review of Scorpion Stings and Snakebites Treated by the French Military Health Service During Overseas Operations Between 2015 and 2017
}

\author{
Aurore Bomba, PharmD ${ }^{1}$; Pascal Favaro, PharmD ${ }^{2}$; Rachel Haus, $\mathrm{MD}^{3}$; Luc Aigle, $\mathrm{MD}^{1,4}$; François-Xavier Jean, $\mathrm{MD}^{5}$; \\ Isabelle Dauphin, PharmD ${ }^{3}$; Pierre Guigon, PharmD ${ }^{2}$; Bruno Fontaine, $\mathrm{MD}^{1,6}$; Marc Puidupin, $\mathrm{MD}^{7}$; \\ Jean-Paul Demoncheaux, $\mathrm{DVM}^{3}$; Sébastien Larréché, $\mathrm{MD}^{8}$ \\ ${ }^{1}$ French Military Health Service Academy, Ecole du Val-de-Grâce, Paris, France; ${ }^{2}$ French Armed Forces Health Products Supply Directorate, Orléans, \\ France; ${ }^{3}$ Central Directorate of the French Military Health Service, Paris, France; ${ }^{4} 10^{\text {th }}$ Military Medical Center, Aubagne, France; ${ }^{5}$ Department of \\ Anesthesiology and Intensive Care, Desgenettes Military Hospital, Lyon, France; ${ }^{6}$ Department of Anesthesiology and Intensive Care, Robert Picqué Mili- \\ tary Hospital, Bordeaux, France; ${ }^{7}$ Military Health Service Academy, Libreville, Gabon; ${ }^{8}$ Department of Medical Biology, Bégin Military Hospital, Saint- \\ Mandé, France
}

Introduction-Depending on their theatre of operation, French soldiers may potentially be exposed to scorpion stings and snakebites. Following the recommendations of a French military health service (FMHS) technical committee for envenomation, the FMHS provides antivenoms appropriate to each deployment. This work aimed to evaluate this risk of envenomation and to assess the antivenoms used by the FMHS in operational theatres since the creation of this committee in 2015.

Methods-Cases were identified based on a review of temporary authorization of use application forms for the use of antivenom. Data were collected retrospectively from these forms, and prescribing physicians were contacted for any missing data.

Results-Between 2015 and 2017, 28 requests for temporary authorization of use were identified: 19 for Scorpifav (Sanofi-Pasteur, Lyon, France) and 9 for Fav-Afrique (Sanofi-Pasteur). The FMHS treated 15 soldiers and 4 civilians for scorpion envenomation with Scorpifav: 15 in Mali, 3 in Chad, and 1 in Niger. Systemic signs were observed in 7 patients. Two soldiers and 7 civilians were treated with Fav-Afrique for ophidian envenomation: 5 in Djibouti, 3 in Mali, and 1 in the Republic of Côte d'Ivoire. These 28 patients were treated without sequelae. Other than moderate erythema that resolved with an antihistamine, no adverse effects were reported. Medical evacuation to France was unnecessary.

Conclusions - This study shows that the risk of envenomation for soldiers on deployment is low but real. Antivenoms used by the FMHS were efficient and well tolerated, preserving the operational capacity of deployed troops.

Keywords: Africa, antivenom, armed forces, envenomation, soldiers

\section{Introduction}

Scorpion and snake envenomation remains a major public health problem in many countries. The global incidence of scorpionism is estimated at more than 1

Corresponding author: Sébastien Larréché, MD, Hôpital d'instruction des armées Bégin, Département de biologie médicale, 69 avenue de Paris, 94160 Saint-Mandé; e-mail: slarreche@ hotmail.fr.

Submitted for publication September 2019.

Accepted for publication January 2020. million envenomations and is associated with approximatively 3000 deaths each year. ${ }^{1}$ Moreover, there are approximately 1.8 to 2.7 million cases of snake envenomation each year, leading to 81,410 to 137,880 deaths and perhaps 3 times that number of permanent disabilities. ${ }^{2}$ In the African sahel, approximately 61,500 scorpion stings and 570 related deaths are estimated to occur each year. ${ }^{3}$ In sub-Saharan Africa, the number of snakebite envenomings and the associated mortality were, respectively, estimated at 314,078 and 7331 each year. ${ }^{4}$ Similarly, in the Middle East, scorpion 
stings were estimated to account for 146,500 envenomations and 800 deaths each year. ${ }^{5}$

Around 30,000 French military personnel are deployed each year in overseas operations, mainly in Africa and the Middle East. Given the nature of their work, military physicians must be prepared to encounter cases of envenomation; nevertheless, there is little epidemiological data with respect to envenomations during military deployments. In 2013, a French soldier on deployment in Mali experienced an envenomation by a Katian spitting cobra (Naja katiensis) while attempting to capture the snake. ${ }^{6}$ The scorpion Leiurus quinquestriatus has recently been implicated in several cases of envenomation among French and Chad soldiers deployed in Mali. ${ }^{7}$ However, these case reports provide insufficient evidence with which to appreciate the importance of envenomations in the field for the French Armed Forces. The United States military estimates the incidence of scorpion stings and snakebites at 46.1 per 10,000 and 4.9 per 10,000 persons, respectively, per month during deployments in Iraq and Afghanistan over the 2005 to 2006 period. $^{8}$

After a request from several United Nations member states, the World Health Organization formally added snakebites to the category A list of priority neglected tropical diseases in June 2017. ${ }^{9}$ It was further noted that antivenom remains the foundation of clinical management for envenomation. The mechanism of action for antivenom is based on the principle of immunotherapy: antibodies produced by an animal that is hyperimmune against venom are purified and then injected into the envenomed patient to promote the elimination of toxic components.

Considering this risk, the French military health service (FMHS) ensures the provision of antivenoms in the field and offers a number of specific treatment recommendations in the event of envenomation. ${ }^{10}$ These treatment guidelines are the product of a technical committee for envenomations (TCE) created in 2015 and composed of military physicians, pharmacists, and veterinarians with expertise in venomous animals or envenomation. Ensuring that soldiers projected to enter exposed environments during overseas operations are adequately informed of the potential risks they face is necessary to minimize the number of envenomations and to avoid otherwise preventable deaths. French armed forces doctrine advocates for the medicalization of the front; consequently, antivenoms are currently available in military treatment facilities (MTFs), which are classified in Role 1, Role 2, and Role 3. Role 1 MTFs are medical posts embedded with combat units and comprise general practitioners, nurses, and paramedics. Role 2 MTFs are field hospitals with surgical teams operating within close proximity to combat units. Role 3 MTFs, on the other hand, are field hospitals with several surgical teams available and are able to perform emergency general, trauma, ophthalmic, and neurological surgery. Role 3 MTFs will usually have a computed tomography scanner available for radiological examinations. Bouffard Military Hospital in Djibouti was, until 2016, considered a Role 3 MTF.

In France, antivenoms for exotic snakes or scorpions do not have marketing authorization. Nevertheless, the French national agency for drug safety grants an exemption to the FMHS, allowing for the use of these antivenoms in the field. In return, a temporary authorization for use (TAU) application must be completed for each patient. The TAU protocol allows early access to drugs currently under development or authorized abroad. Although envenomations are not under epidemiological surveillance by the FMHS, the burden posed by envenomation to the French armed forces can nonetheless be studied through a review of TAU applications.

The primary aim of this study was to review TAU application forms for antivenoms administrated overseas by French military physicians during the 2015 to 2017 period to evaluate the risk (ie, frequency and severity) and characteristics of envenomations treated by the FMHS. The secondary aim of this study was to assess the effectiveness and the tolerance of antivenoms chosen by the TCE.

\section{Methods}

This study was approved by the national commission for informatics and liberties (\#2157078). This commission is responsible for ensuring the protection of personal data contained in computer files or papers, both public and private.

All TAU application forms for antivenom use in overseas deployments received by the department of regulatory affairs and pharmacovigilance, branch of supply of health products of the armed forces, from January 1, 2015 to December 31, 2017, were reviewed retrospectively. Where necessary, physicians who completed the form were contacted individually by email or by phone to retrieve additional information; all requests were answered. Protocols published by the TCE specify the indications for antivenom use, as well as patient aeromedical evacuation in the event of snakebite or scorpion sting. Although TCE experts are sometimes asked for advice via phone consultation, the decision to administer antivenom is at the discretion of the treating physician.

For each patient, the following data were extracted: antivenom type; demographic data (eg, age, sex, nationality, military or civilian status); date, location, and context of envenomation; animal species (if known); time between sting or bite and subsequent arrival to a medical treatment facility (Roles 1, 2, or 3); anatomic site of the sting/bite; local signs (eg, pain, edema, erythema, blister, necrosis, local bleeding, sensory troubles); systemic signs (eg, fever, bleeding, neurological disorder, respiratory signs, 
Table 1. Gradation of scorpion envenomation

\begin{tabular}{ll}
\hline Grade & Clinical signs \\
\hline 1 & $\begin{array}{l}\text { Pain with or without local signs (edema, paresthesia, } \\
\text { erythema) }\end{array}$ \\
& Autonomic effects \\
& - parasympathetic response: bradycardia, diarrhea, \\
& hypersalivation, bronchial hypersecretion, miosis, \\
& vomiting, abdominal pain \\
& - sympathetic response: agitation, hypertension, \\
hyperthermia, mydriasis, tachycardia, priapism \\
Pulmonary acute edema \\
Hypotension, cardiogenic shock
\end{tabular}

digestive signs, organ failure); electrocardiographic and laboratory abnormalities; severity according to gradations edited by the TCE for scorpion sting (Table 1) and snakebite (Table 2); details of antivenom: initial dosage, number of injections, noted adverse effects; and patient outcome.

Data were entered into a spreadsheet protected with a password (Microsoft Excel).

Qualitative variables were expressed as absolute values and, when appropriate, as percentages. Quantitative variables were expressed as medians (interquartile range).

\section{Results}

Twenty-eight TAU application forms were completed by French military physicians between 2015 and 2017. Two antivenoms were used during the study period: Scorpifav (Sanofi-Pasteur, Lyon, France) was used 19 times (68\%), and Fav-Afrique (Sanofi-Pasteur, Lyon, France) was used 9 times (32\%). Scorpifav is a polyvalent antivenom for Old World scorpions (genus Androctonus, Buthus, and Leiurus), and Fav-Afrique is a polyvalent antivenom for sub-Saharan African snakes (genus Echis, Bitis, Naja, and
Dendroaspis). All cases concerned sub-Saharan Africa. No events were recorded in the Middle East. During the period of the study, 23,892 French soldiers were deployed in Africa.

\section{USE OF SCORPIFAV}

Based on data extracted from TAU applications, the median age of FMHS patients with scorpionism was 28 y (interquartile range: $23-32$; range: 19-48). There were 17 $(89 \%)$ male and $2(11 \%)$ female patients (Table 3). Fifteen patients (79\%) were French soldiers, and the incidence rate of scorpionism was 5.9 per 10,000 French deployed soldiers in Africa.

Although some scorpions were captured or seen, no formal identification was made.

Fifteen patients (79\%) were stung in Mali (11 in Tessalit and 4 in Gao), 3 (16\%) in Chad, and $1(5 \%)$ in Niger. Four (21\%) patients were treated in Role 1 facilities, and 15 patients (79\%) were admitted to Role 2 facilities.

Eight stings concerned the upper limbs: 6 were on the fingers, 1 on the hand, and 1 on the forearm. Seven stings concerned the lower limbs: 3 were on the ankle, 2 on the knee, and 2 on the thigh or buttock. The anatomical signs were unknown for 4 patients. Clinical signs are presented in Table 4.

According to the gradation framework described by the TCE, 17 patients $(90 \%)$ presented with grade 1 scorpionism, and 2 patients $(10 \%)$ presented with grade 2 . There was no grade 3 scorpion envenomation. All patients received a dose of ten 1-mL ampoules of Scorpifav. No patient received a second dose. One adverse event (5\%) was reported: a patient who experienced nonsevere erythema $3 \mathrm{~d}$ after Scorpifav administration. The patient was seen again on the eighth day after being stung because urticaria was still present. The patient received symptomatic treatment with an antihistamine, dexchlorpheniramine

Table 2. Gradation of snake envenomation

\begin{tabular}{|c|c|c|c|c|}
\hline Grade & Local syndrome & Hemostasis & Neurological signs ${ }^{a}$ & General signs \\
\hline 0 & $\begin{array}{l}\text { Moderate pain } \\
\text { Fang marks } \\
\text { No edema }\end{array}$ & $\begin{array}{l}\text { No coagulopathy } \\
\text { No bleeding }\end{array}$ & No & No \\
\hline 1 & $\begin{array}{l}\text { Major pain } \\
\text { Edema not exceeding the first joint }\end{array}$ & $\begin{array}{l}\text { No coagulopathy }{ }^{\mathrm{b}} \\
\text { No bleeding }\end{array}$ & No & No \\
\hline 2 & Edema exceeding the first joint & $\begin{array}{l}\text { Coagulopathy }{ }^{\mathrm{b}} \\
\text { Bleeding at bite site or hematuria }\end{array}$ & Yes & Hypotension \\
\hline 3 & $\begin{array}{l}\text { Edema reaching the limb root } \\
\text { Necrosis }\end{array}$ & $\begin{array}{l}\text { Coagulopathy } \\
\text { Bleeding (other than grade 2) }\end{array}$ & Yes & $\begin{array}{l}\text { Shock } \\
\text { Respiratory failure } \\
\text { Acute renal injury }\end{array}$ \\
\hline
\end{tabular}

\footnotetext{
${ }^{a}$ Neurological signs: involvement of cranial pairs, abolition of osteotendinous reflexes, muscular or respiratory paralysis.

b Coagulopathy: platelets $<150 \mathrm{~g} \cdot \mathrm{L}^{-1}$, prothrombin rate $<45 \%$, fibrinogenemia $<1 \mathrm{~g} \cdot \mathrm{L}^{-1}$, or abnormal whole blood coagulation test.
} 
Table 3. Case details of scorpion stings treated by the French military health service between 2015 and 2017

\begin{tabular}{|c|c|c|c|c|c|c|c|}
\hline $\begin{array}{l}\text { Case } \\
\text { number }\end{array}$ & $\begin{array}{l}\text { Date of } \\
\text { envenomation }\end{array}$ & Status & $\begin{array}{l}\text { Age } \\
(y)\end{array}$ & Sex & Envenomation context & Location & $\begin{array}{l}\text { Time to } \\
\text { care }\end{array}$ \\
\hline 1 & June 2015 & French military & 30 & Male & Sting at night on operation & Role 2, Gao, Mali & 6 to $12 \mathrm{~h}$ \\
\hline 2 & July 2015 & French military & 28 & Male & In camp & Role 1, Tessalit, Mali & $<6 \mathrm{~h}$ \\
\hline 3 & November 2015 & Chadian civilian & 31 & Female & In camp & Role 2, N'Djamena, Chad & Unknown \\
\hline 4 & June 2016 & French military & 31 & Male & Sitting outside at night & Role 1, Tessalit, Mali & $<1 \mathrm{~h}$ \\
\hline 5 & June 2016 & French military & 22 & Male & Moving rocks & Role 2, Tessalit, Mali & $<6 \mathrm{~h}$ \\
\hline 6 & June 2016 & French military & 20 & Male & Moving rocks & Role 2, Tessalit, Mali & $<6 \mathrm{~h}$ \\
\hline 7 & August 2016 & French military & 28 & Male & Sitting outside at night & Role 2, Tessalit, Mali & $<1 \mathrm{~h}$ \\
\hline 8 & September 2016 & French military & 28 & Male & Handling outside & Role 2, Tessalit, Mali & $<1 \mathrm{~h}$ \\
\hline 9 & October 2016 & French military & 48 & Female & Unknown & Role 2, N'Djamena, Chad & $<6 \mathrm{~h}$ \\
\hline 10 & October 2016 & Malian civilian & 19 & Male & Unknown & Role 2, Tessalit, Mali & $<6 \mathrm{~h}$ \\
\hline 11 & October 2016 & French military & 21 & Male & Unknown & Role 1, Tessalit, Mali & $<1 \mathrm{~h}$ \\
\hline 12 & November 2016 & French military & 33 & Male & On operation & Role 2, N'Djamena, Chad & $<6 \mathrm{~h}$ \\
\hline 13 & June 2017 & French military & 32 & Male & Putting on his shoe & Role 2, Gao, Mali & $<1 \mathrm{~h}$ \\
\hline 14 & June 2017 & Nigerian civilian & 28 & Male & Picking up animal & Role 1, Madama, Niger & $<1 \mathrm{~h}$ \\
\hline 15 & June 2017 & French military & 21 & Male & Moving sandbag & Role 2, Tessalit, Mali & $<1 \mathrm{~h}$ \\
\hline 16 & June 2017 & Malian civilian & 23 & Male & Taking out trash & Role 2, Tessalit, Mali & $<6 \mathrm{~h}$ \\
\hline 17 & July 2017 & French military & 42 & Male & On operation & Role 2, Gao, Mali & $<6 \mathrm{~h}$ \\
\hline 18 & July 2017 & French military & 38 & Male & Unknown & Role 2, Gao, Mali & $<6 \mathrm{~h}$ \\
\hline 19 & July 2017 & French military & 25 & Male & Moving sandbag & Role 2, Tessalit, Mali & $<1 \mathrm{~h}$ \\
\hline
\end{tabular}

(Polaramine), which resulted in the resolution of erythema within $24 \mathrm{~h}$. All patients were discharged within 24 to 48 $\mathrm{h}$ without sequelae. There was no medical evacuation to France.

\section{USE OF FAV-AFRIQUE}

The median age of FMHS patients with snakebite was $20 \mathrm{y}$ ( interquartile range: $10-31$; range: $2-44$ ). There were 6 male and 3 female patients. Two patients were soldiers: 1 French and 1 Dutch (both in Gao, Mali). The incidence rate of snakebite was 0.4 per 10,000 French deployed soldiers in Africa. Other patients were civilians (Table 5).

Table 4. Clinical signs frequency of patients stung by scorpions

\begin{tabular}{lll}
\hline & Patients $(n)$ & Percentage \\
\hline Pain & 19 & 100 \\
Local signs & & \\
$\quad$ Edema & 9 & 47 \\
$\quad$ Erythema & 6 & 32 \\
$\quad$ Paresthesia & 6 & 32 \\
Systemic signs & & \\
$\quad$ Abdominal pain & 1 & 5 \\
$\quad$ Dizziness & 1 & 5 \\
$\quad$ Dysgeusia & 1 & 5 \\
$\quad$ Faintness & 1 & 5 \\
$\quad$ Nausea & 1 & 5 \\
$\quad$ Sweating & 1 & 5 \\
\hline
\end{tabular}

Seven cases occurred in 2015, and 2 in 2016. There were no snakebites treated by the FMHS in 2017.

Five patients (56\%) were treated in Djibouti (each in Role 3 facilities), 3 (33\%) in Mali (1 in a Role 1 facility in Tessalit and 2 in a Role 2 facility in Gao), and 1 in the Republic of Côte d'Ivoire (a French civilian in a civilian polyclinic). In this last case, the Role 1 facility in Abidjan was quickly contacted by the Pisam Clinic in Abidjan. The latter, however, did not have Fav-Afrique in stock because it is supplied directly by the Pasteur Institute, which does not provide night or weekend coverage; in this case, the patient was bitten on a Saturday night.

Eight patients were bitten by viperids, with the species determined by the physician on the basis of a clinical assessment of the patients' presenting signs and symptoms. The French civilian was bitten by an elapid, a western green mamba (Dendroaspis viridis), in the Republic of Côte d'Ivoire. The patient was a herpetologist and was able to identify the snake to the physician. In the case of the 2 soldiers and the French civilian, the delay between bite and receipt of antivenom was less than $6 \mathrm{~h}$. In the case of local civilians, the interval between being bitten and the receipt of antivenom was not described in 4 cases; in the other 2 cases, the patient was treated on the fourth or sixth day after the bite.

Six patients were bitten on the upper limb: 4 on the hand, 1 on the left annular, and the last on the elbow. The anatomical site of the bite was unknown for 3 patients. The 
Table 5. Case details of snakebites treated by the French military health service between 2015 and 2017

\begin{tabular}{|c|c|c|c|c|c|c|c|c|}
\hline $\begin{array}{l}\text { Case } \\
\text { number }\end{array}$ & Date & Status & $\begin{array}{l}\text { Age } \\
(y)\end{array}$ & Sex & Location & $\begin{array}{l}\text { Envenomation } \\
\text { context }\end{array}$ & $\begin{array}{l}\text { Species } \\
\text { involved }\end{array}$ & $\begin{array}{l}\text { Time to } \\
\text { care }\end{array}$ \\
\hline 1 & April 2015 & French military & 29 & Male & Role 2, Gao, Mali & In operation & Viperid & $<6 \mathrm{~h}$ \\
\hline 2 & June 2015 & $\begin{array}{l}\text { Dutch military } \\
\text { of the UN Forces }\end{array}$ & 44 & Male & Role 2, Gao, Mali & $\begin{array}{l}\text { Cleaning the } \\
\text { surrounding area } \\
\text { and an evacuation } \\
\text { pipe }\end{array}$ & Viperid & $<6 \mathrm{~h}$ \\
\hline 3 & June 2015 & French civilian & 38 & Male & $\begin{array}{l}\text { Pisam clinic, } \\
\text { Abidjan, } \\
\text { Côte d'Ivoire }\end{array}$ & Unknown & $\begin{array}{l}\text { Elapid } \\
\text { Dendroaspis } \\
\text { viridis }\end{array}$ & $<6 \mathrm{~h}$ \\
\hline 4 & June 2015 & Local civilian & 31 & Male & Role 3, Djibouti & Unknown & Viperid & Unknown \\
\hline 5 & July 2015 & Local civilian & 8 & Male & Role 3, Djibouti & Unknown & Viperid & Unknown \\
\hline 6 & July 2015 & Local civilian & 10 & Female & $\begin{array}{l}\text { Role 1, Tessalit, } \\
\text { Mali }\end{array}$ & Unknown & Viperid & Unknown \\
\hline 7 & $\begin{array}{l}\text { December } \\
2015\end{array}$ & Local civilian & 25 & Male & Role 3, Djibouti & Unknown & Viperid & 5 or $6 \mathrm{~d}$ \\
\hline 8 & January 2016 & Local civilian & 20 & Female & Role 3, Djibouti & Unknown & Viperid & $4 \mathrm{~d}$ \\
\hline 9 & March 2016 & Local civilian & 12 & Female & Role 3, Djibouti & Unknown & Viperid & Unknown \\
\hline
\end{tabular}

patient bitten by a $D$ viridis quickly presented with systemic signs with vomiting and sensory neurological disorder with dysesthesia of the 4 limbs. This envenomation was classified as grade 2. The clinical and biological signs associated with viperid bites seen by the FMHS are presented in Table 6.

According to the TCE gradation framework, 5 patients presented with grade 2 and 4 patients with grade 3 envenomation. The patient bitten by $D$ viridis first received two 10$\mathrm{mL}$ vials of Fav-Afrique. A third vial was administered at $\mathrm{H}+1$, and a fourth at $\mathrm{H}+2$. The Dutch soldier received 4 ampoules at $\mathrm{H} 0,2$ at $\mathrm{H}+5 \mathrm{~h} 30$, and 2 at $\mathrm{H}+8 \mathrm{~h} 30$. Other

Table 6. Clinical and biological signs frequency of patients bitten by viperids

\begin{tabular}{|c|c|c|}
\hline & Patients (n) & Percentage \\
\hline Pain & 4 & 50 \\
\hline \multicolumn{3}{|l|}{ Local signs } \\
\hline Edema & 5 & 56 \\
\hline Local bleeding $^{\mathrm{a}}$ & 3 & 33 \\
\hline \multicolumn{3}{|l|}{ Systemic signs } \\
\hline Sweating & 1 & 11 \\
\hline Systemic bleeding $^{\mathrm{b}}$ & 4 & 44 \\
\hline \multicolumn{3}{|l|}{ Biological signs } \\
\hline $\begin{array}{l}\text { Coagulopathy (platelets } \\
<150 \mathrm{~g} \cdot \mathrm{L}^{-1}, \mathrm{TP}<45 \%, \\
\text { fibrinogenemia }<1 \mathrm{~g} \cdot \mathrm{L}^{-1} \\
\text { or abnormal whole blood } \\
\text { coagulation test) }\end{array}$ & 6 & 66 \\
\hline
\end{tabular}

${ }^{a}$ Local bleeding: bleeding at the bite site.

b Systemic bleeding: epistaxis, hemoptysis or mucocutaneous bleeding. patients received only an initial dosage: 3 patients received 2 vials, 3 patients 1 vial, and the last only half a vial. None of these patients developed any side effects, and there were no deaths. None of these patients required surgical intervention, and no medical evacuation to France was needed.

\section{Discussion}

Envenomation is a rare but potentially significant risk to French soldiers during active deployments. Scorpion stings were the main cause of envenomation among French soldiers, with 15 cases reported between 2015 and 2017. Similarly, the US military reports a preponderance of scorpion stings during deployments. ${ }^{8}$ In our study, there was no grade 3 severity (ie, corresponding to a severe case of envenomation by scorpion sting). Severe cases were rare among healthy adults and concerned mostly children. Snakebite envenomations were rarer (only 1 case involving a French soldier) but were more serious than envenomation by scorpion sting. Four patients with grade 3 snakebite presented with bleeding. Moreover, this study illustrates the humanitarian work of the FMHS, which can also be mobilized to support civilian patients. This is not the original purpose of the FMHS, but it may be required to do so in certain circumstances such as emergency relief or actions to prevent or fight epidemics.

Scorpion stings were found to have occurred during the hot and humid months in western Africa and during the cool season in Chad. Snakebites, on the other hand, occurred throughout the year. Most scorpion stings occurred in Mali, where scorpionism was also described among the civilian population. ${ }^{11,12}$ According to these 
studies, most scorpion stings occurred at night, during the summer months, and at home.

The cluster observed for snakebites in Djibouti can be explained by the presence of a Role 3 FMHS facility in this country. This Role 3 facility is known to be well equipped with antivenom, whereas local civilian health facilities often suffer from a lack of supply. The absence of cases in 2017 can be explained by the transformation of this Role 3 hospital into a joint medical center. The reduction in staff and resources led to a refocusing of the hospital activity on medical support for French and Djiboutian armies and thus to a reduction of the aid capacity of this MTF for local populations. Most cases seen by this facility involved bites by Echis pyramidum. This species can cause a severe defibrinating coagulopathy. ${ }^{10,13}$ There were no reported cases of scorpion or snake envenomation in the Middle East.

The circumstances surrounding cases of envenomation varied considerably. Most snakebites or scorpion stings were the result of inappropriate military behavior, including attempts to capture and handle these animals. Ahead of deployment, personnel should be informed of appropriate preventive measures to reduce their risk of exposure: 1) do not handle dead or live animals, 2) wear gloves when moving stones or garbage, 3 ) check clothing before wearing it, and 4) inspect the premises before setting up camp. In the latter case, an ultraviolet lamp may be used to highlight naturally fluorescent scorpions.

Nevertheless, stings or bites can also occur during missions. One case of scorpion envenomation was reported during combat in the Tagab district, Afghanistan. ${ }^{14}$ Such cases may have a direct operational impact. In most cases, soldiers were treated early, usually within $6 \mathrm{~h}$. Civilian patients, on the other hand, were sometimes seen by the MTF several days after a snakebite. Nonetheless, no deaths were reported. The effectiveness of these antivenoms is evidenced by the absence of surgery or medical evacuations despite clinical signs of envenomation. These results are congruent with data reported by the US military. ${ }^{15}$

The antivenoms used in our study, Scorpifav and FavAfrique, are F(ab')2-based antivenoms. Several studies have shown that $F\left(a b^{\prime}\right) 2$-based antivenoms are well tolerated after administration. ${ }^{16-19}$ Our results are consistent with those reported in the literature. All patients stung by scorpions received the TCE-recommended dose of Scorpifav (ie, $101 \mathrm{~mL}$ vials). It should be noted that there is the potential for dosing errors with Scorpifav, particularly with the administration of insufficient doses if only 1 or 2 vials are injected. Four patients received a lower FavAfrique dosage than that recommended by the TCE (ie, 2 vials for the first injection). We do not know the reasoning behind the administration of this lower dosage, but it should be noted that no sequelae or deaths have been reported with this lower dosage.

The only adverse effect identified and potentially attributable to the treatment by Scorpifav was erythema. Antivenom safety is essential because military physicians often work in isolated conditions. The tolerance shown in our series of case reports supports the use of these agents in Role 1 treatment facilities. Indeed, the antivenoms described here can be used quickly in the field with minimal risk of harm, thus limiting the severity of envenomations and avoiding costly medical evacuations.

Unfortunately, Sanofi-Pasteur decided to stop the production of Fav-Afrique, and the last available stock expired in June 2016. The TCE has chosen to replace Fav-Afrique with 2 freeze-dried antivenoms: Inoserp Pan Africa and Inoserp MENA (Inosan Biopharma, Madrid, Spain). These antivenoms can be stored at room temperature, thus providing field-adapted products.

\section{LIMITATIONS}

This work has limitations. First, as in other retrospective studies, the accuracy of our data was limited by the variable quality of filling out the TAU recording form. As such, despite the appearance of a standardized data collection instrument, variability in the entry of details may lead to a lack of uniformity in our data. Moreover, a more systematic approach to the identification of venomous animals involved in each case would make it possible to know the precise species involved and allow for the adaptation of antivenom coverage ${ }^{2}$ accordingly. Additionally, the short window for patient follow-up (less than a week) makes it difficult to identify late complications, such as serum sickness. Furthermore, we did not collect data about other envenomations not treated by antivenoms but that might nonetheless pose a nuisance for soldiers, such as vesicant beetle stings (eg, genus Paederus).

\section{Conclusions}

This study has reported the burden posed by scorpion stings and snakebites during military operations undertaken by the French Armed Forces. Although this risk remains low for soldiers, the potential risk of severe cases necessitates the stocking of antivenom, especially in case of snakebites. Antivenoms used by the FMHS between 2015 and 2017 were efficient and well tolerated, allowing their use in Role 1 facilities and preserving the operational capacity of deployed troops. Future studies should endeavor to assess the efficacy and practicalities associated with the use of new freeze-dried products in the specific context of military deployment. 
Author Contributions: Study concept and design (AB, PF, SL); acquisition of data (AB, RH, LA, FXJ, ID, PG); analysis of data (AB, PF, BF, MP, JPD, SL); drafting of manuscript (AB, SL); critical revision of manuscript (AB, PF, RH, LA, FXJ, ID, PG, BF, MP, JPD, SL); approval of final manuscript (AB, PF, RH, LA, FXJ, ID, PG, BF, MP, JPD, SL).

Financial/Material Support: None.

Disclosures: None.

\section{References}

1. Rodrigo C, Gnanathasan A. Management of scorpion envenoming: a systematic review and meta-analysis of controlled clinical trials. Syst Rev. 2017;6(1):74.

2. Gutiérrez JM, Calvete JJ, Habib AG, Harrison RA, Williams DJ, Warrell DA. Snakebite envenoming. Nat Rev Dis Primer. 2017;3:17063.

3. Habib AG, Kuznik A, Hamza M, Abdullahi MI, Chedi BA, Chippaux JP, et al. Snakebite is under appreciated: appraisal of burden from West Africa. PLoS Negl Trop Dis. 2015;9(9):e0004088.

4. Chippaux JP. Estimate of the burden of snakebites in subSaharan Africa: a meta-analytic approach. Toxicon. 2011;57(4):586-99.

5. Chippaux JP. Global incidence of snake and scorpion envenoming. Med Sci (Paris). 2009;25(2):197-200.

6. Demoncheaux JP, Faure N, Boni M, Mérigaud JP, Lemoine T, Michel R. Opération Serval : enseignements vétérinaires et perspective. Médecine et armées. 2015;4(43): 352-61.

7. Dewar C, Meusnier J, Larréché S. Envenimation scorpionique chez des militaires français en poste isolé au Nord Mali : à propos de cinq cas. Ann Fr Med Urg. 2016;6:431-4.

8. Shiau DT, Sanders JW, Putnam SD, Buff A, Beasley W, Tribble DR, et al. Self-reported incidence of snake, spider, and scorpion encounters among deployed U.S. military in Iraq and Afghanistan. Mil Med. 2007;172(10): 1099-102.

9. Chippaux JP. Snakebite envenomation turns again into a neglected tropical disease! J Venom Anim Toxins Incl Trop Dis. 2017;23:38.
10. Larréché S, Aigle L, Puidupin M, Jean FX, Tanti M, Hupin C, et al. Animaux venimeux terrestres en opérations extérieures : présentation des principaux risques et du Comité technique des envenimations. Médecine et armées. 2018;1(46):63-72.

11. Goyffon M, Dabo A, Coulibaly SK, Togo G, Chippaux JP. Dangerous scorpion fauna of Mali. J Venom Anim Toxins Incl Trop Dis. 2011;18(4):361-8.

12. Dabo A, Golou G, Traoré MS, Diarra N, Goyffon M, Doumbo O. Scorpion envenoming in the north of Mali (West Africa): epidemiological, clinical and therapeutic aspects. Toxicon. 2011;58(2):154-8.

13. Larréché S, Jean FX, Benoit A, Mayet A, Bousquet A, Vedy S, et al. Thromboelastographic study of the snakebiterelated coagulopathy in Djibouti. Blood Coagul Fibrinolysis. 2018;29(2):196-204.

14. Donat N, Masson Y, Villevieille T, Pelletier C, Rousseau JM, Plancade D, et al. A case of combat-related scorpion envenomation in Afghanistan. Mil Med. 2011;176(4):472-4.

15. Heiner JD, Bebarta VS, Varney SM, Bothwell JD, Cronin AJ. Clinical effects and antivenom use for snake bite victims treated at three US hospitals in Afghanistan. Wilderness Environ Med. 2013;24(4):412-6.

16. Chippaux JP, Massougbodji A, Stock RP, Alagon A. Investigators of African Antivipmyn in Benin. Clinical trial of an $\mathrm{F}(\mathrm{ab}$ ')2 polyvalent equine antivenom for African snake bites in Benin. Am J Trop Med Hyg. 2007;77(3): $538-46$.

17. Dzikouk GD, Ngoa LS, Thonnon J, Dongmo AB, Rakotonirina VS, Rakotonirina A, et al. Titrage comparatif de trois sérums antivenimeux utilisés contre les serpents d'Afrique sub-saharienne. Bull Soc Pathol Exot. 2002;95(3): 144-7.

18. Natu VS, Kamerkar SB, Geeta K, Vidya K, Natu V, Sane S, et al. Efficacy of anti-scorpion venom serum over prazosin in the management of severe scorpion envenomation. J Postgrad Med. 2010;56(4):275-80.

19. Ghalim N, El-Hafny B, Sebti F, Heikel J, Lazar N, Moustanir R, et al. Scorpion envenomation and serotherapy in Morocco. Am J Trop Med Hyg. 2000;62(2):277-83. 